\title{
Jordanian High School EFL Teachers' and University EFL Instructors' Perceptions of the Reading Comprehension Content in EFL Textbooks
}

\author{
Nasser M. Freahat \\ English Language Department, Al-Imam Mohammad Ibn Saud Islamic University, Riyadh, Saudi Arabia \\ Oraib Hmoud Al-Faoury \\ English Language Department, Al-Imam Mohammad Ibn Saud Islamic University, Riyadh, Saudi Arabia
}

\begin{abstract}
The study aimed to examine the attitudes towards the appropriateness and the difficulty level of the reading content in secondary stage EFL textbooks in Jordan and an introductory EFL textbook taught in the Jordanian universities. The study involved EFL university instructors, secondary EF teachers, secondary stage students, and freshmen university students. The researcher developed a questionnaire to survey students' perceptions on the appropriateness of the reading material in the secondary stage and for preparing students to university level reading demands. The researcher also interviewed university EFL instructors and secondary EFL teachers to add more credibility to the findings of the study. The results of the questionnaire showed that the students viewed "the appropriateness of the reading content in AP11 and AP12 as "suitable", their "preparation for the university reading level" and their "preparation with reading strategies and their experience with the reading content in NHWP" "fairly suitable". Moreover, EFL teachers and instructors viewed the reading content in the three textbooks as generally easy but still difficult for the students. EFL teachers indicated that the majority of the students leave the secondary schools unprepared for the university. Similarly, the university EFL instructors indicated that the majority of the freshmen university students were usually unprepared for the reading demands at the university level.
\end{abstract}

Index Terms — reading comprehension, reading skills, postsecondary reading

\section{INTRODUCTION}

Reading is appreciated in any community because, among other reasons, it is the skill that distinguishes literate from illiterate people. Without adequate reading comprehension, students pursuing higher education are vulnerable to failure (Giuliano and Sullivan, 2007). Therefore, students' ability to read well becomes essential for their academic success.

In the past decades, researchers discovered a mutual relationship between a student's academic reading skills and academic success. Williamson (2008) contends that successful students can be unprepared after high school because their reading skills are insufficient for postsecondary texts. He concludes that there is a substantial gap in text demand between widely used high school textbooks and typical postsecondary textbooks. Sengupta (2002) states that the teaching of reading in schools has not helped foster the ability to interpret and evaluate texts and has left the undergraduate who comes to university with an insufficient inheritance from the school system. These learners have minimal reading skills and strategies and are ill equipped to handle demands of academic reading.

Textbooks have a major influence on what is learned in classrooms. In the foreign language situation the textbook is an essential part in the teaching process. Thus, it is essential to ensure that students' reading be efficient and that all reading material be at an appropriate level of difficulty; that is, it must be neither too difficult for the students nor too easy to provide challenging practice (Leslie and Caldwell, 1997).

The teaching of English as a Foreign Language in Jordan is an important objective which aims at developing different language skills. Although English in Jordan has received a great emphasis, and although reading is the core of Jordan's EFL curriculum in schools and universities, the use of English is still on the professional scale. On the other hand, a large number of freshman university students in Jordan complain about the difficulty of the reading component in EFL courses and there is an observable weakness on the part of students in the reading comprehension skills.

One of the compulsory courses taught at Jordanian universities is the English Language Course (LC) 099 which is the first introductory EFL course students study at the university in case the student could not pass an EFL proficiency test. By teaching LC 099, universities exert an effort on the improvement of reading comprehension. In spite of this emphasis on reading comprehension, many instructors of English in the Jordanian universities complain that many of their students are poor readers. In spite of all the changes that are taking place in the Jordanian educational system, there is an observable weakness in reading comprehension skills on the part of the students. A number of university students 
fail to deal with the whole text as a unit. This weakness impairs their utilization of texts within and outside the academic context (Al Haddad, 1996).

\section{A. Statement of the Problem}

In Jordan, many university students, after studying English for twelve years at school, suffer real problems because of the new demands placed on them. This means that a percentage of university students is somehow unable to conform to the situation at the university. The deficiency in the students' reading can be attributed to different factors including the preparation of the students at school and the gap between the school and the university textbooks. To ascertain whether the gap is purely a performance gap or whether there is also a textual gap requires that students' performance and the perceptions of secondary school EFL teachers and Language Center instructors be studied. The researcher selected LC 099 textbook for analysis because it is the first course taught for a large percentage of university students who cannot pass the English language proficiency test. The researcher assumes that the reading content in LC 099 textbook is more difficult and more demanding than the reading content of grade 11 and grade 12 textbooks. This study addressed the following questions:

1. To what degree do LC 099 students feel Action Pack (AP) 11 and AP 12 prepared them for the reading demands of university courses?

2. To what degree do secondary school EFL teachers and Language Center (LC) 099 instructors feel that their students are prepared for the reading demands in university courses?

\section{B. Purpose of the Study}

This study aimed at finding out how the secondary school EFL curriculum in Jordan prepares students for university level reading skills. In other words, the study aimed to examine the perceptions of grade 12 EFL teachers, students at Yarmouk University studying LC 099, and instructors of LC 099 at Yarmouk University towards the preparedness of high school students to university with EFL reading skills.

\section{Significance of the Study}

The findings of this study are significant for those who are concerned with teaching reading comprehension in secondary schools and at universities, selecting EFL courses, and evaluating students' performance in reading.

The study becomes more important when one considers the importance of the transitional period between the last year at school and the first year in the university. This study came out with results that make the transition of the learners from school to university smoother. This study presents recommendations for textbook selection and for the teaching of reading comprehension at this critical stage.

In addition, considering the views of secondary school students and teachers, LC 099 students and instructors about the appropriateness of the reading material added more insights to the study. These opinions presented data that can be used by The Ministry of Education, Universities, and EFL teachers and instructors for improving the teaching of reading and the selection of the appropriate textbooks.

Moreover, to the best of the researchers' knowledge, no study has been conducted in the Jordanian EFL situation that tackles whether or not AP 12 prepares students to university reading demands. Therefore, it was a primary purpose of this study to identify the extent to which AP 11 and AP 12 prepare students for the university reading demands. Such a study provided essential data about the alignment between the reading content in AP series and New Head Way Plus Pre_intermediate (NHWP).

\section{LITERATURE REVIEW}

The current study investigated the appropriateness and the difficulty levels of the reading content in the Jordanian secondary stage EFL textbooks (Action Pack 11 and Action Pack 12) and in an EFL textbook taught for first year students at Yarmouk University (New Headway Plus Pre-intermediate). This stage constitutes students who move from secondary school (high school) to postsecondary education and known as "Transition to postsecondary education".

The secondary school provides the last opportunity for most students to obtain guidance in reading proficiency. Macklin (1978) indicates that reading instruction at the secondary level might be perceived as helping the reader to acquire information and develop specific techniques needed for handling the reading materials in each discipline. Roe, Stoodt and Burns (1978) report that secondary level textbooks in various areas tend to have high readability levels in relation to the reading abilities of the students who are expected to read them. They add that evidence indicates that a wide variety of difficulty exists within single texts and that many texts do not have a gradation of difficulty from the beginning to the end.

Adelman (1999) states that for a large number of students, the years they spent at high school are not enough to prepare them to be successful at college. He reports that previous research shows that the most important predictor of success in college is the quality of the high school curriculum. Therefore, it is essential that the content of high school textbooks be evaluated time to time to ensure that they are focused on the demanding skills needed by postsecondary education. 
The American College Testing Program (ACT, 2006) stresses the importance of reading for success in college and workplace yet reports that half of high school graduates are ready for college level reading. A frequently heard criticism of secondary school students and university freshmen is their weak reading ability. Although reading may not be the main source of information for many university students, it is still a vital learning tool. Poor readers struggle to learn and are frequently blocked from taking more challenging courses. Therefore, reading is considered an essential component of college or university readiness. ACT Inc.

It is essential that the difficulty of the textbook be appropriate for the reading abilities of the students for whom the books are intended. Harris- Sharples (1983) indicates that one needs to consider a variety of factors within the book in relation to the students when attempting to select a textbook appropriate for a student. These would include such aspects of difficulty as the vocabulary and syntax, the degree of students' interest, conceptual load, and the like. However, the persistent question is what the best match between the students' level of reading and the level of readability should be.

Many researchers in the Jordanian educational context evaluated different Jordanian EFL textbooks. Magableh(2000) evaluated the functional language textbook for the first commercial secondary class, the results of her study revealed that the material was interesting and logically sequenced. The exercises suited the students' level and their interests. The content of the textbook was easy and attractive for both students and teachers. On the other hand, the findings revealed lack of colours, grammar, role play, lack of punctuation, spelling, phonetic transcription of new words, tests, visual aids and dialogues.

Karsou (2005) evaluated Action Pack textbooks (1-5) in Jordan. The result of the study revealed that the respondents agreed on the suitability of Action Pack textbooks in motivating learners to communicate; the appropriateness of the reading materials to the learners' needs and interests; the methods of teaching were relevant to the general and specific objectives; the teacher's book provided teachers with key answers and finally; the general aspects of Action Pack textbooks were highly appropriate. Concerning the weaknesses of Action Pack textbook, the findings indicated that the objectives were less appropriately relevant to the learner's real life situations; listening and speaking skills were inappropriate for the learner's abilities; the vocabulary items were not provided with the phonetic transcription.

The literature in the area of reading textbook analysis and the perceptions of the learners and teachers is very vast. A large number of studies have been done on textbook analysis and educators' opinions of such textbooks in Jordan or elsewhere. Unfortunately, very little research has actually examined the reading material of high school in contrast to those of university to determine if there is a gap between them. Al- Haddad (1996) examined the attitudes of twelfth grade students in Jordan toward reading. The respondents were found to have neutral attitudes toward reading on each factor except for literary students who scored a slightly positive rating on the utility factor.

Maaka and Ward (2000) explored community college students' inability to learn from assigned content area readings. They examined the community college students' perceptions regarding reading motivation, skills, strategies, and comprehension. The study showed that the students were not aware of the kind of critical reading they needed to be doing. They did not spend as much time as the instructor felt was necessary doing reading, and were not motivated to complete the readings. On the other hand, the instructors' views did not correspond with the student views on the opinion whether the students were effective readers.

ACT (2006) tested the reading comprehension skills of approximately 1.2 million high school students, who graduated in 2005 across The United States. The reading part of the test aimed at investigating the preparedness of the tested students to the college level reading demands. The results of the test indicated that only $51 \%$ of the high school graduates were ready for college-level reading.

In 2002-03, The National Council of Teachers of English (ACTE) sent about 10,900 writing and 5,200 reading surveys to secondary- and postsecondary-level teachers across the United States. Twenty percent of those educators completed and returned the survey about the most important or as a prerequisite for success in college courses. Secondary-level teachers were also asked to indicate whether each skill was or was not taught in the class they named. Patterson and Deur (2006) reported the results of this survey which was mainly designed to find out what writing and reading skills are taught by high school teachers and expected of incoming students by instructors of common first-year college courses. The survey revealed a good correspondence between practice and expectations. While the high school teachers and college instructors responding to the surveys mostly agree on which writing and reading skills are most important, the college instructors appear to place more stress on grammar and usage than do the high school teachers. At the same time, both groups gave relatively low importance ratings to many higher-order reading skills related to evaluating or judging text. The survey findings also suggested that curriculum differentiation, or tracking, continues to influence the kind of instruction some students receive which raises the important question of whether all students are being adequately equipped with appropriate writing and reading skills.

Henry (2006) reported at The Community College of Ontario first year students' perceptions of their preparedness for the literary tasks required of them in their first- Year College programs and compared those views with the perceptions of their program instructors. The findings of this study showed that college students and instructors were satisfied with the preparation of students for the literacy requirements of colleges. The study also indicated that college students struggle with spelling and with using grammar correctly. Moreover, students with college preparation high school courses reported having more trouble than those with university preparation courses to meet college literacy requirements. 
Williamson (2008) elaborated a continuum of text demand for postsecondary endeavours. He examined whether 11th- and 12th-grade students' exposure to high school texts sufficiently prepares them for textual material they might encounter in their postsecondary endeavours. The study demonstrated substantial differences between the materials that high school students are expected to read and the materials they may encounter after high school. High school material reflected a substantially higher text demand from students in the postsecondary lives.

\section{METHODOLOGY}

\section{A. The Population of This Study}

First: the population of the first secondary (eleventh grade) students at Jordanian public schools in Jerash Directorate of Education in the academic year 2011/2012. They were 3564 students with 1890 female students in 28 schools and 1674 males in 25 schools.

Second: the population of the second secondary (twelfth grade) students at Jordanian public schools in Jerash Directorate of Education in the academic year 2011/2012. They were 3357 students with 1674 female students in 28 schools and 1683 students in 25 schools.

Third: the population of the first year students at Yarmouk University who studied CL 099 in the first semester of the academic year 2011/2012. They were 2711 students distributed in 35 sections.

Fourth: the population of the Secondary stage English language teachers in Jerash Directorate of Education in the academic year 2011/2012. They were 42 female and 44 male teachers.

Fifth: the population of the English language instructors at the Language Centre in Yarmouk University who taught CL 099 in the first semester of the academic year 2011/2012. They were 16 instructors.

\section{B. The Sample of the Study}

The sample of the study was twofold: students' sample, and teachers' and instructors' sample. Three different groups of students were used. For the purpose of selecting the sample, the researcher followed the cluster sampling technique where three clusters were identified (11th grade students, 12th grade students, and CL 099 students). Sections were purposefully assigned from each cluster. The first group was 274 eleventh grade students in Jerash directorate of education (148 females and 126 males) in the scientific, literary, information technology (IT), and Health Management streams. Four sections in four public female schools and four sections in four public male schools were chosen purposefully since the students in these eight schools were from different areas of Jerash Directorate of Education which includes Jerash city and surrounding areas.

The second group was 300 twelfth grade students in Jerash directorate of education (163 females and 137 males) in the scientific, literary, information technology (IT), and Health Management streams. Four sections in four public female schools and four sections in four public male schools were chosen purposefully since the students in these eight schools were from different areas of Jerash Directorate of Education which includes Jerash city and surrounding areas. Table (1) below shows the distribution of the 11th and 12th grade students samples.

TABLE 1:

THE DISTRIBUTION OF THE 11TH AND 12TH GRADE STUDENT PARTICIPANTS.

\begin{tabular}{lllllll}
\hline Level & \multirow{2}{*}{ Gender } & Scientific & Literary & IT & $\begin{array}{l}\text { Heath } \\
\text { Management }\end{array}$ & Total \\
\hline 11th & Male & 31 & 33 & 35 & 27 & 126 \\
Grade & Female & 37 & 33 & 41 & 37 & 148 \\
\hline 12th & Male & 33 & 36 & 37 & 31 & 137 \\
Grade & Female & 37 & 41 & 43 & 42 & 163 \\
\hline
\end{tabular}

The third group was 310 freshmen students who were studying CL 099 at Yarmouk University Language Center during the first semester of the academic year 2011/2012 (183 females and 127 males). Six sections at Yarmouk University language centre were purposefully assigned for the purpose of this study.

The same CL 099 sample responded to a questionnaire about the appropriateness and difficulty level of the reading content in the secondary stage textbooks, how it prepared them for the university reading level, and their reading experience with LC 099 textbook. The original number was 310 students, but some students who did not study the Jordanian EFL curriculum at the secondary stage, the students who had language courses or training before they joined LC 099, and students who were not at the first year level were excluded. Therefore, the final number of the respondents was 226 freshmen students who were studying LC 099 at Yarmouk University.

Regarding the teachers, ten English language teachers who were teaching the secondary stage in the first semester of the academic year 2011/2012 (5 male teachers and 5 female teachers) were interviewed to investigate their perceptions of the appropriateness and difficulty level of the reading content in AP11 and AP12 and how this content helps prepare the students for the university reading level. All of those teachers were teaching the secondary stage with their experience ranging from four to nineteen years. They hold at least B.A. in the English language and literature. Some of them hold diploma or M.A. in TEFL and English linguistics. 
Regarding the instructors, right English language instructors at Yarmouk University's Language Centre were interviewed to investigate their perceptions of the appropriateness and difficulty level of the reading content in NHWP and how this content helps prepare the students for reading in other courses at the university level. All of those instructors were teaching LC 099 during the first semester of the academic year 2011/2012 with their experiences ranging from 6 to more than 30 years. They hold M.A. in English linguistics, English literature and some of them have $\mathrm{PhD}$ in TEFL.

\section{Textbooks under Study}

Forr a number of reasons, the reading content in grade 11, grade 12, and LC 099 were chosen as the levels of textbooks to analyze. Grade 11 and 12 make the secondary stage in the Jordanian educational system. On the other hand, LC 099 is the first EFL course that the majority of the university freshmen study if compared to other courses. The period including the secondary stage and university first year represents the transition from school to university. The researchers were interested in this stage when they planned their research as this stage is a crucial one in the students' academic life and it has not been studied as shown by the literature review. Therefore, it is hoped that this study presents an insight into some aspects of this stage by investigating the appropriateness and the difficulty level of the reading content in the textbooks under study.

\section{The Questionnaire}

The researchers developed a questionnaire to tackle LC 099 Yarmouk University Students' perceptions regarding the appropriateness and the difficulty level of the reading content in AP 11 and AP 12 and how these textbooks help prepare the students for the university reading level. The questionnaire also sought the respondents' perceptions on the appropriateness and the difficulty level of reading content in NHWP.

The questionnaire was distributed for first year university students who studied AP11 and AP12 in grades 11 and 12. The researcher distributed the questionnaire after only 43 days of their enrolment in the university so that they would have a good idea about NHWP and they could make a comparison between what they studied at the secondary stage and at university.

The questionnaire consisted of twenty five items distributed over four dimensions. The four dimensions are preparation for the university reading level, appropriateness of reading in Action Pack series, preparation with reading strategies and, students' experiences with the reading content of the NHWP.

The questionnaire used the following scale to determine the level of agreement with the items in the questionnaire:

"Strongly Agree" = 5 points

"Agree" = 4 points

"Uncertain" = $=3$ points,

"Disagree" = $=2$ points,

"Strongly disagree" = 1 point.

For score interpretation, the researcher adopted the following scale to represent the means of items and domains when presenting and discussing the results of the study in chapters four and five:

TABLE 2:

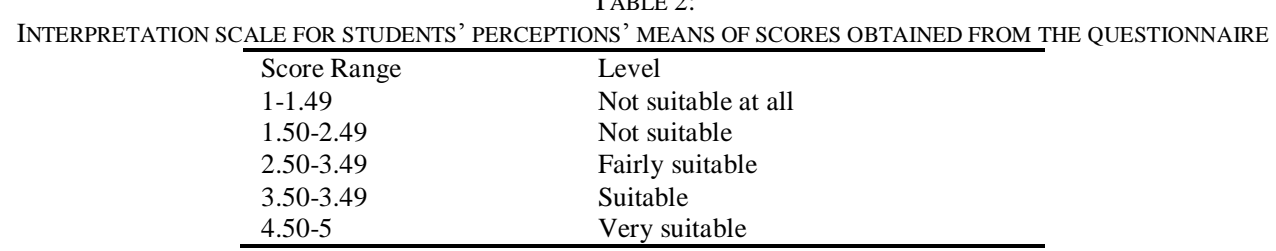

\section{E. Validity of the Questionnaire}

In order to establish the content validity for the domains of the questionnaire and the items in each domain, a jury of EFL specialists were asked to validate the contents of the questionnaire. They emphasized that some items were a repetition of other items, they suggested simplifying some difficult words and adding some negative items since all items hypothesized that the students' perceptions towards the reading content in the textbooks were positive. The researcher took the suggestions of these specialists into consideration and composed the questionnaire in its final form.

Regarding construct validity, the researchers administered the questionnaire to a pilot sample of 50 students twice within a period of two weeks after which they calculated the correlation coefficients between the items on one hand, and between the scale and the dimensions on the other hand. Values of the correlation coefficient of the items in the first dimension (Preparation for the University Reading Level) with the whole dimension ranged between 0.67-0.78, and that the values of the correlation coefficient with the scale ranged between $0.47-0.78$. The values of the correlation coefficient of the items in the second dimension (Appropriateness of the Reading Content in AP Series) with the whole dimension ranged between $0.71-0.85$ and that the values of the correlation coefficient with the scale ranged between 0.50-0.64. The values of the correlation coefficient of the items in the third dimension (Preparation with Reading Strategies) with the whole dimension ranged between $0.75-0.84$ and that the values of the correlation coefficient with 
the scale ranged between $0.58-0.64$. The values of the correlation coefficient of the items in the fourth dimension (Students' Experience with the Reading Content of New Headway Plus Pre-intermediate) with the whole dimension ranged between $0.81-0.87$ and that the values of the correlation coefficient with the scale ranged between $0.48-0.54$.

In order to establish the internal validity of the questionnaire, the researchers calculated the correlation coefficients between the dimensions of the questionnaire with each other. The researchers also calculated the correlation coefficients between the dimensions of the questionnaire with the total score of the whole questionnaire. The correlation coefficients between the dimensions of the study ranged between 0.11 and 0.81 , and that the correlation coefficient between each dimension and the total score for the questionnaire 0.62 and 0.75 . All of the aforementioned coefficients in Table 9 indicate significant correlations which indicate that the questionnaire was valid for what it was built to measure.

\section{F. Reliability of the Questionnaire}

To establish the reliability of the questionnaire, the researcher administered the questionnaire to a pilot group of one section of LC 099 using the test/retest method. The pilot application has shown Pearson's Correlation Coefficient as an indication of the stability index through the two applications of the research instrument. The Pearson Correlation value of the test/retest stability index was 0.86 while the Cronbach's Alpha Internal Consistency on the first application on the test was 0.90. The internal consistency for the scale was 0.91 whereas it ranged between $0.86-0.91$ for the dimensions. The table also shows that the stability index value for the scale was 0.86 and it ranged between $0.84-0.87$ for its dimensions. The aforementioned values indicated the possibility of adopting the questionnaire for the final application on the targeted sample of the research.

\section{G. Interviews}

The researchers carried out structured interviews with Yarmouk University Language Centre Instructors who taught LC 099 during the first semester of the academic year 2011-2012. Similar interviews were conducted with Secondary Schools EFL teachers. The questions of the secondary school teachers' interview related to the appropriateness and the difficulty level of the reading content in AP11 and AP12, and whether the reading content in the textbooks help prepare the students for university level reading. On the other hand, the interview of LC 099 instructors at Yarmouk University asked some questions about the appropriateness and the difficulty level of the reading content in NHWP, and whether it prepares the students for the reading demands in other university courses.

The interviews were done individually and each interview lasted for approximately 20 minutes. The interviews were recorded and the teachers' and instructors' responses were analyzed qualitatively and classified and then conclusions were drawn.

\section{H. Validity of the Interviews}

To insure the validity of the interview, the jury of EFL specialists was asked to state whether the interview questions were enough and appropriate. The specialists suggested editing some questions and making more consistency between the two interviews. Furthermore, the specialists suggested that the researcher should inquire about topics that were not raised in the original interviews. The researchers therefore edited some questions and added others. The final version of the two interviews consisted of 7 interview questions.

\section{Data Analysis}

Descriptive statistics (percentages, means, and standard deviations, etc) were used for analyzing the students' responses to the questionnaire items. The statistical computer software used in analyzing and computing data obtained from the questionnaire was Statistical Package for Social Sciences (SPSS).

The data in the second question consisted of ten- teacher interviews and eight-instructor interviews. The researchers coded and analyzed the data in a timely manner after collecting it. The researchers read through the transcripts to gain a holistic picture of the data. Then they read the interview transcripts separately looking for patterns between the interviews and making notes from which he generated a list of topics. After becoming familiar with the data, they organized it into categories. Some of these categories were predetermined by the interview questions, and some categories emerged during the collection and analysis of the interview data.

When the researchers were satisfied with the categories, they selected representative quotations that exemplified what was repeated by many participants. The researchers reviewed the categories and compared the instructor's categories to the teacher's categories to see where they confirmed or disconfirmed each other.

The teacher interview data revealed three main themes: student-textbook match and appropriateness, preparation for higher education, and strengths and weaknesses of the reading content in AP11 and 12 and change recommendations. The instructors' interview revealed similar themes related to NHWP. These themes were: student-textbook match and appropriateness, preparation for university courses, and strengths and weaknesses of the reading content in NHWP and change recommendations

\section{RESUlts AND ANALYSIS}

\section{A. Results Related to the First Question}


The first research question was: To what degree do LC 099 students feel Action Pack 11 and Action Pack 12 prepared them for the reading demands of university courses?

To answer this question, the researcher used a questionnaire which consisted of four dimensions. The students' opinions were computed using means, standard deviations, rank order, frequencies and percentages of each item. Table 3 presents the means and standard deviations of the students' responses to the questionnaire items distributed into the four domains of the questionnaire.

TABLE 3:

RANK ORDER, MEANS AND STANDARD DEVIATIONS OF THE STUDENTS' RESPONSES TO THE DIMENSIONS OF THE QUESTIONNAIRE

\begin{tabular}{|l|l|l|l|}
\hline Rank & Domain & Mean & Standard deviation \\
\hline 1. & Appropriateness of the reading content in AP11 and AP12 & 3.51 & 0.95 \\
\hline 2. & Students' experience with the reading content of the NHWP & 3.25 & 1.02 \\
\hline 3. & Preparation with level reading strategies & 3.24 & 0.97 \\
\hline 4. & Preparation for the university reading level & 2.73 & 1.02 \\
\hline 5. & Mean of means & 3.17 & 0.72 \\
\hline
\end{tabular}

Table 3 shows that students perceive the "Appropriateness of AP11 and AP12 and its preparing students to higher education" fairly suitable. The means of the students' responses to the questionnaire dimensions ranged between (3.51 and 2.73) with standard deviations that ranged between (0.95 and 1.02). It is clear that the dimension of the "appropriateness of the reading content in AP11 and AP12" was viewed as the best dimension "suitable" whereas the dimension of "Preparation for the university reading level" was in the last position of all dimensions.

Tables 4 to 7 present the rank order, means and standard deviations of the items of each dimension. Table 4 presents the rank order, means and standard deviations of the students' responses to the "Preparation for the university reading level" dimension.

TABLE 4:

RANK ORDER, MEANS AND STANDARD DEVIATIONS OF THE STUDENTS' RESPONSES TO THE “PREPARATION FOR THE UNIVERSITY READING LEVEL” ITEMS

\begin{tabular}{|l|l|l|l|}
\hline $\begin{array}{l}\text { Rank } \\
\text { No. }\end{array}$ & Item content & $\begin{array}{l}\text { Mean } \\
\text { Scores }\end{array}$ & $\begin{array}{l}\text { Standard } \\
\text { Deviation }\end{array}$ \\
\hline 1. & I wish I could have more reading classes in the secondary stage & 2.97 & 1.46 \\
\hline 2. & $\begin{array}{l}\text { The reading content of Action Pack 1 and Action Pack 12 does not prepare } \\
\text { students to the university study in English }\end{array}$ & 2.82 & 1.35 \\
\hline 3. & $\begin{array}{l}\text { The reading texts in Action Pack 11 and 12 have a lot concepts which are not } \\
\text { pertinent to my needs }\end{array}$ & 2.77 & 1.51 \\
\hline 4. & $\begin{array}{l}\text { Not enough reading strategies and skills are taught in the secondary school if } \\
\text { compared to the reading strategies and skills taught at university }\end{array}$ & 2.76 & 1.28 \\
\hline 5. & $\begin{array}{l}\text { The reading content of New Headway Plus Pre-Intermediate is not appropriate for } \\
\text { me to learn }\end{array}$ & 2.67 & 1.37 \\
\hline 6. & $\begin{array}{l}\text { There is weak integration between secondary stage reading content and that of this } \\
\text { course }\end{array}$ & 2.60 & 1.37 \\
\hline & $\begin{array}{l}\text { I can hardly deal with the reading material in New Headway Plus Pre-Intermediate } \\
\text { without remediation or additional training }\end{array}$ & 2.56 & 1.33 \\
\hline 7. & Mean of means & 2.73 \\
\hline
\end{tabular}

Table 4 shows that the means ranged between (2.56 and 2.97) with standard deviations that ranged between (1.33 and 1.46). The highest mean was for "I wish I could have more reading classes in the secondary stage", whereas the "I can hardly deal with the reading material in New Headway Plus Pre Intermediate without remediation or additional training" had the lowest mean (2.56 and 2.97). The general mean is (2.73) which shows that the students think that the reading content in the textbooks is "fairly suitable" in preparing the students for the university reading level.

Regarding, the appropriateness of the reading content in Action Pack 11 and Action Pack 12, table 5 presents the rank order, means and standard deviations of the students' responses to the "Appropriateness of the reading content in Action Pack 11 and Action Pack 12" domain items.

TABLE 5:

RANK ORDER, MEANS AND STANDARD DEVIATIONS OF THE STUDENTS' RESPONSES TO THE “APPROPRIATENESS OF THE READING CONTENT IN ACTION PACK11 AND ACTION PACK 12"

\begin{tabular}{|l|l|l|l|}
\hline Rank No. & Item Content & Mean Scores & Standard deviation \\
\hline 1. & Action Pack 11 and 12 include diverse texts which are at a variety of difficulty levels & 3.77 & 1.28 \\
\hline 2. & The reading content of Action Pack 11 and 12 was appropriate for me & 3.67 & 1.18 \\
\hline 3. & $\begin{array}{l}\text { Having known the difference between the secondary stage reading and university } \\
\text { reading, I am satisfied with the way Action Pack 11 and Action Pack 12 prepared me }\end{array}$ & 3.60 & 1.26 \\
& Action Pack 11 and 12 provide sufficient activities that improve student's reading & 3.42 & 1.25 \\
\hline 4. & The reading texts in Action Pack 11 and 12 are likely to motivate the students to read & 3.32 & 3.32 \\
\hline 5. & The texts in Action Pack 11 and 12 are written at an appropriate difficulty level & 3.16 \\
\hline 7. & Total Mean & 3.51 & 0.95 \\
\hline
\end{tabular}


Table 5 shows that the means ranged between (3.32 and 3.77) with standard deviations that ranged between (1.24 and 1.28). The highest mean was for "Action Pack 11 and 12 include diverse texts which are at a variety of difficulty levels", whereas the "The texts in Action Pack 11 and 12 are written at an appropriate difficulty level" had the lowest mean (3.32 and 3.77). The general mean is (3.51) which shows that the students think that the reading content in Action Pack 11 and Action Pack 12 is suitable (appropriate).

Regarding the preparation with reading strategies, table 6 presents the rank order, means and standard deviations of the students' responses to the "Preparation with reading strategies" dimension.

TABLE 6:

RANK ORDER, MEANS AND STANDARD DEVIATIONS OF THE STUDENTS' RESPONSES TO THE “PREPARATION WITH READING STRATEGIES” ITEMS

\begin{tabular}{|l|l|l|l|}
\hline $\begin{array}{l}\text { Rank } \\
\text { No. }\end{array}$ & Item Content & $\begin{array}{l}\text { Mean } \\
\text { scores }\end{array}$ & $\begin{array}{l}\text { Standard } \\
\text { deviation }\end{array}$ \\
\hline 1 & $\begin{array}{l}\text { Action Pack 11 and Action Pack 12 provided me with effective strategies to } \\
\text { succeed with reading at higher education such as skimming and scanning }\end{array}$ & 3.33 & 1.28 \\
\hline 2 & $\begin{array}{l}\text { Studying Action Pack 11 and Action Pack 12 made me able to make } \\
\text { connections between my prior knowledge and the reading texts }\end{array}$ & 3.31 & 1.23 \\
\hline 3 & $\begin{array}{l}\text { Studying Action Pack 11 and Action Pack 12 made me able to interpret } \\
\text { information from graphs, charts, and diagrams }\end{array}$ & 3.28 & 1.15 \\
\hline 4 & $\begin{array}{l}\text { Studying Action Pack 11 and Action Pack 12 made me able to recognize main } \\
\text { ideas by selecting topic sentences }\end{array}$ & 3.21 & 1.21 \\
\hline 5 & $\begin{array}{l}\text { Studying Action Pack 11 and Action Pack 12 made me able to recognize } \\
\text { cause-effect relationships in the texts }\end{array}$ & 3.21 & 1.20 \\
\hline 6 & $\begin{array}{l}\text { Studying Action Pack 11 and Action Pack 12 made me able to recognize } \\
\text { narration and chronological sequences in the texts }\end{array}$ & 3.10 & 1.18 \\
\hline & Total Mean & 3.24 & 0.97 \\
\hline
\end{tabular}

Table 6 shows that the means ranged between (3.10 and 3.33) with standard deviations that ranged between (1.18 and 1.28). The highest mean was for "Action Pack 11 and 12" provided me with effective strategies to succeed with reading at higher education such as skimming and scanning" whereas "Studying Action Pack 11 and 12 made me able to recognize narration and chronological sequences in the texts" had the lowest mean (3.10 and 3.33). The general mean is (3.24) which shows that the students perceive their preparation with reading strategies "fairly suitable".

Regarding students' experience with the reading content of New Headway Plus Pre-intermediate, table 7 presents the rank order, means and standard deviations of the students' responses to the "Students' experience with the reading content of New Headway Plus Pre-intermediate" dimension.

TABLE 7:

RANK ORDER, MEANS AND STANDARD DEVIATIONS OF THE STUDENTS' RESPONSES TO THE “STUDENTS' EXPERIENCE WITH THE READING CONTENT OF NHWP"

\begin{tabular}{|l|l|l|l|}
\hline $\begin{array}{l}\text { Rank } \\
\text { No. }\end{array}$ & Item content & $\begin{array}{l}\text { Mean } \\
\text { Scores }\end{array}$ & $\begin{array}{l}\text { Standard } \\
\text { deviation }\end{array}$ \\
\hline 1. & I read the texts in New Headway Plus Pre-intermediate slowly & 3.46 & 1.31 \\
\hline 2. & $\begin{array}{l}\text { I do not understand a large percentage of the words in the reading texts of New } \\
\text { Headway Plus Pre-intermediate }\end{array}$ & 3.29 & 1.19 \\
\hline 3. & $\begin{array}{l}\text { I find the sentences in the reading texts of New Headway Plus Pre-intermediate } \\
\text { difficult to understand }\end{array}$ & 3.21 & 1.20 \\
\hline 4. & $\begin{array}{l}\text { I find the reading texts in New Headway Plus Pre-intermediate non-coherent when } \\
\text { reading. }\end{array}$ & 3.20 & 1.20 \\
\hline 5. & $\begin{array}{l}\text { The information in the texts of New Headway Plus Pre-intermediate is densely } \\
\text { presented that it complicates my understanding of the contents }\end{array}$ & 3.19 \\
\hline 6. & I find the reading texts in New Headway Plus Pre-intermediate incomprehensible & 3.17 \\
\hline 7. & Total Mean & 3.25 \\
\hline
\end{tabular}

Table 7 shows that the means ranged between (3.17 and 3.46) with standard deviations that ranged between (1.29 and 1.31). The highest mean was for "I read the texts in New Headway Plus Pre-intermediate slowly", whereas the lowest mean was for "I find the reading texts in New Headway Plus Pre-intermediate incomprehensible" had the lowest mean (3.17 and 3.46). The general mean shows that the students perceive their experience with the reading content of NHWP "fairly suitable".

\section{B. Results Related to the Second Question:}

The second research question is "To what degree do secondary school EFL teachers and LC 099 instructors feel that the reading content in their students' textbooks is appropriate for their students' levels and prepare them for university reading level?"

To answer this question, the researcher conducted two sets of interviews. The first interview was with 10 secondary EFL teachers in Jerash Directorate of Education and the other was with 8 LC 099 instructors at Yarmouk University Language. It is worth mentioning that all of the interviews were audio-recorded except those were the interviewees refused being recorded for. Furthermore, and as mentioned earlier in chapter three, the data obtained from the 
interviews were analyzed qualitatively. The results related to this research question are presented in two sections: Instructor interview analysis, and teacher interview analysis.

\section{First: Instructors' Interview Analysis}

The instructors' interview data revealed three main themes. The instructors discussed the appropriateness of the reading content in NHWP for students' reading levels, the extent to which the reading content in NHWP prepares students for other courses, and strengths and weaknesses of the reading content in NHWP and recommendations for change. Generally speaking, the instructors' perceptions were similar for each of the three themes.

In regard to their views on the appropriateness of the reading content to their students' needs, the instructors agreed on the fact that the reading material is too simple beyond the desired level of freshmen university students, however they all expressed that the majority of their students were still too weak to be at the readability level of the textbook.

The instructors were asked about their perception of to what extent they thought the reading extent in NHWP helps prepare students for other university courses. However, a number of instructors indicated that the reading material needs to be more demanding to prepare the students for academic endeavors at the university.

Regarding the strengths of the reading content in NHWP, the majority of the instructors agreed on many points including: new topics, sufficient exercises, controlled vocabulary, and the attractive layout. Regarding the weaknesses, the instructors also agreed on many points including: the lack of critical reflection exercises, the variation in the lengths of the passages, the difficult vocabulary, and the focus on the western culture. Regarding the need to change or modify the reading material in NHWP, instructors suggested tailoring the material to meet the students' needs in the fields of study, adding some texts with different topics, dealing with different cultures and more appealing to students with different interests and adding some opportunities to employ strategies such as inferring, contextualizing, predicting, summarizing and retelling.

Like the instructors' interview, the teachers' interview data revealed three main themes. The instructors discussed the appropriateness of the reading content in AP11 and AP12 for students' reading levels, the extent to which the reading content in AP11 and AP12 prepares students for university reading level, and strengths and weaknesses of the reading content in AP11 and AP12 and recommendations for change.

Generally speaking, the teachers showed some agreement on many points regarding the appropriateness of the reading material in AP11 and AP12 to the reading levels of the 11th and 12th grades. The teachers indicated that there are great differences among the reading levels of their students. Generally, the teachers expressed a mismatch between the students' reading levels and the level of the reading material they study. There was almost a consensus among the interviewed teachers that about less than half of the students cannot read well. Furthermore, number of instructors indicated that AP11 matches its students' reading levels more than AP12 does.

Although some teachers are not very well familiar with the reading demands students face at the university level, many of them indicated that the reading material in the secondary stage textbooks (AP11 and AP12) includes various texts which prepare the student for other fields. The majority of the teachers indicated that they are aware that most of their students suffer at the university level because of their reading abilities and they expressed the need for change.

Regarding the weaknesses, the most common points mentioned by the interviewed teachers were:

1. Some texts are quite easy to read and understand.

2. Many topics are interesting and related to students' needs.

3. There are many exercises that give the students the chance to practice reading skills.

4. The reading texts are suitable in length.

Regarding the weaknesses of the reading material in the secondary stage, the interviewees agreed on the following points:

1. The texts are too difficult for the levels of the students.

2. The inclusion of the new vocabulary is not clear in AP12. The new words are difficult and limited.

3. Not all topics are relevant for the case of the Jordanian students. And some topics are quite boring for the students as they do not understand much of their content.

Regarding their suggestions to change or modify the reading material in AP11 and 12, teachers suggested enriching the types of reading texts and using more literary texts, adding different kinds of exercises that teach the students how to read instead of only practicing reading, making controlled lists of vocabulary for each new unit and involving the students in choosing the topics.

\section{DisCUSSIONS AND CONCLUSION}

\section{A. Discussion of the Results of the First Question}

This study investigated the students' opinions of "Action Pack 11" and "Action Pack 12" regarding the following dimensions: the appropriateness of the reading content in AP11 and AP12, students' experience with the reading content of the NHWP, preparation with level reading strategies, and preparation for the university reading level.

The results show that "the appropriateness of the reading content in AP11 and AP12" is "suitable" with means between (3.32 and 3.77) and a total mean of (3.51). The respondents believe that AP11 and AP12 include a variety of texts at a variety of reading difficulty levels that motivate the students to read, with sufficient activities for practice. Regarding the "preparation for the university reading level", the students think that AP11 and AP12 are "fairly suitable" 
with means between (2.56 and 2.97) and a general mean of (2.73). The respondents believe that the reading content in AP11 and AP12 was somehow suitable for them and it fairly helps preparing the students for the university level reading, yet they believe it would have been better if they had had more reading classes in the secondary stage.

With regards to the "preparation with reading strategies", the results show that the respondents view this dimension "fairly suitable" with means between (3.10 and 3.33) with a general mean of (3.24). The students believe that studying AP11 and AP12 fairly empowered them with reading strategies like skimming, scanning, making connections, interpreting charts, graphs and diagrams, recognizing main ideas, and recognizing relationships and sequences among the reading passages. The results of this dimension agrees with the findings of Henry (2006) who found that in spite of the troubles they struggle to meet college reading level, college students were satisfied with the preparation of the students for the literacy requirements of the colleges.

As a result of being prepared to the university level reading, the students view their "experience with the reading content in NHWP" "fairly suitable" with means of (3.46 and 3.17) and a general mean of (3.25). The students reported that they read the texts fairly slowly, they do not understand much of the words and sentences in the texts, and that they find the reading passages a bit difficult and the information is quite dense in the reading passages. The negative responses of the respondents indicate their lack of proper preparation to the university level reading. The results in this regard are congruent with ACT (2006) which indicated that only about half of high school graduates were ready for college-level reading.

\section{B. Discussion of the Results of the Second Question}

In regard to the instructors' views on the appropriateness of the reading content to their students' needs, the instructors agreed on the fact that the reading material is too simple beyond the desired level of freshmen university students, but they all expressed that the majority of their students were too weak to be at the readability level of the textbook.

Regarding the reading levels of the students, the instructors expressed their students' weak reading abilities. Some of the instructors, especially those with short experience, expressed their surprise at the reading levels of their students when they started teaching them. One instructor stated: "I was too much shocked since the majority of the students lag behind their expected reading level". Other instructors especially those with long experience stated that they are familiar with the very weak reading levels of the students, one experienced instructor stated that "I have never been surprised by my students reading levels as I already know how weak the majority of freshmen students are. I wonder what hose students have been doing during their school years". One instructor was an exception of this norm. She believed that students are good enough to cope with the reading demands of their levels. She stated that "I was surprised by my students' reading levels, since they were able to understand, extract and respond appropriately to the basic content of different types of reading texts, and they were able to explain the main points in the texts with reasonable precision".

The instructors explained that the reading content in NHWP is very easy if the students work hard. One instructor went into details saying that "the texts are short and simple, there are too many exercises to enrich students' reading, but the problem is only with our students". Some instructors, however, were more optimistic regarding the match between students' reading levels and the textbook difficulty. One instructor summed it up when she said "I guess it's acceptable, but due to time and space limitations, the students are not given a fair chance to practice their reading skills, so I think if we have enough time, the students' reading levels would be improving!".

Some instructors were conscious of the details regarding students' level and how to match that to the students "I think that most of the texts are suitable for the students' reading levels. Yet, there are other texts which are very long and these have to be modified in order to suit the students' linguistic competence. An example of these texts is Megapolitis."

The instructors were asked about their perception of the extent they thought the reading content in NHWP helps prepare students for other university courses. The majority of the instructors indicated that the reading material in NHWP is helpful in preparing the students for other courses. One instructor indicated that "this textbook helps students to read simple texts requiring a simple and direct exchange of information". Another instructor stated that "it is perfect for university students as it builds up their knowledge of the topics". However, other instructors indicated that the reading material needs to be more demanding to prepare the students for academic endeavours at the university.

Regarding the strengths of the reading content in NHWP, the majority of the instructors agreed on many points including: interesting and up-to-date topics, well-prepared exercises that give the chance for practice, controlled vocabulary, the simplicity of the reading passages, and the layout of the textbook. Regarding the weaknesses, the instructors also agreed on many points including the lack of opportunities given to the students to reflect on the texts, the negative variation in the lengths of the texts, difficult vocabulary and the focus on the western culture.

Regarding the need to change or modify the reading material in NHWP, the instructors suggested tailoring the material to meet the students' needs in the fields of study which entails going for ESP which some instructors did not agree on. One instructor stated: "however, this choice is not so good either, because the teachers are not specialized in various fields. Nevertheless, I would choose more demanding texts." Another instructor insisted on "adding some texts with different topics, dealing with different cultures and more appealing to students with different interests; and adding some opportunities to employ strategies such as inferring, contextualizing, predicting, summarizing and retelling." 
Like the instructors' interview, the teachers' interview data revealed three main themes. The instructors discussed the appropriateness of the reading content in AP11 and AP12 for students' reading levels, the extent to which the reading content in AP11 and AP12 prepares students for university reading level, and strengths and weaknesses of the reading content in AP11 and AP12 and recommendations for change.

Generally, the teachers showed some agreement on points regarding the appropriateness of the reading material in AP11 and AP12 to the reading levels of the 11th and 12th grades. The teachers indicated that there are great differences among the reading levels of their students. "Some of the students are quite comfortable with the level of the textbook while others suffer", one teacher said. Teachers in general expressed a mismatch between the students' reading levels and the level of the reading material they study. There was almost a consensus among the interviewed teachers that about less than half of the students cannot read well. Furthermore, a number of instructors indicated that AP11 matches its students' reading levels more than AP12 does.

Although some teachers are not very well familiar with the reading demands students meet at the university level, many of them indicated that the reading material in the secondary stage textbooks includes various texts which prepare the student for other fields. One teacher pointed out that "there are many kinds of reading passages that include science, technology, biology, history and literature". The majority of the teachers indicated that they were aware that most of their students suffer at the university level because of their reading abilities and they expressed the need for change. The results in this regard are congruent with Williamson (2008) which demonstrated substantial differences between the materials that high school students are expected to read and the materials they may encounter after high school.

Regarding the weaknesses, the most commonly cited points mentioned by the interviewed teachers were the simplicity of the reading passages, the suitable length of the reading passages, the interesting topics that are relevant to students' needs, and the sufficient number of exercises that gives the students the chance to practice the reading skills. Regarding the weaknesses of the reading material in the secondary stage, the interviewees agreed on the following points: the difficulty of the texts if compared with weak level of the students, the unclear inclusion of vocabulary, and the irrelevance of some topics for the students' lives,

Regarding their suggestions to change or modify the reading material in AP11 and 12, the teachers suggested enriching the types of the texts and using more literary texts, adding more exercises that teach students reading strategies, controlling the new vocabulary items by using vocabulary lists, and involving the students in choosing the topic.

In light of the results of this study, the researchers recommended that the Ministry of Education and universities should solicit teachers' and instructors' opinions before, during, and after preparing or adopting a textbook. The researchers also suggested initiating the communication between secondary schools and universities to bridge the reading gap between schools and universities and to enable schools prepare the students for the expected reading demands at the university level. They also suggested conducting other research studies on larger samples and in other areas of transition from school to university in all fields of study.

\section{REFERENCES}

[1] ACT, Inc. (2006). Assessing the college readiness in reading of eighth- and ninth-grade students using ACT's EXPLORE®. Iowa City, IA: Author. Retrieved December 29th, 2012 from Academic Search Premier EBSCO Database (AN: ED510538).

[2] Adelman, C. (1999). Answers in the textbook: academic intensity, attendance patterns and bachelor's degree attainment. Washington, DC: U.S. Department of Education

[3] Al-Haddad, A. (1996). Reading attitudes reported by twelfth grade students in Jordan. Unpublished PhD dissertation, University of Nebraska. Retrieved January 3rd, 2012 from Proquest database

[4] Giuliano, B., \& Sullivan, J. (2007). Academic holism: Bridging the gap between high school and college. American Secondary Education, 35(3), 7- 18. Retrieved September 8th, 2011 from Academic Search Premier EBSCO database (AN: 12474362).

[5] Haines, S. (2009). Action Pack 11. London: York Press.

[6] Haines, S. (2009). Action Pack 12. London: York Press.

[7] Harris- Sharples, D. (1983). A study of the match between students reading ability and textbook difficulty during classroom instruction. Unpublished PhD dissertation, Harvard University, Harvard. Retrieved January 20th, 2012 from Proquest database.

[8] Henry, N. (2006). Perceptions of college students and instructors on students' preparedness for the literacy demands of college. Unpublished Master thesis: Queens University. Retrieved January 24th, 2012 from Proquest database.

[9] Karsou, M. (2005). An evaluation of Action Pack textbooks as perceived by Jordanian English language supervisors, teachers, and instructors. Unpublished Master thesis, The University of Jordan, Amman, Jordan.

[10] Leslie, L., Caldwell, J. (1997). Qualitative Reading Inventory 2. New York: Longman.

[11] Maaka, M., Ward. S. (2000). Content area reading in community college classroom. Community College Journal of Research and Practice, 24(2), 107-125. Retrieved August 17th 2011 from Academic Search Premier EBSCO database (AN: 2794546).

[12] Macklin, M. (1978). Content area reading as a process for finding personal meaning. Journal of Reading, 22, $211-213$. Retrieved October 24th 2011 from Academic Search Premier EBSCO database (AN: EJ 195997).

[13] Magableh, W. (2000). An evaluation of functional English language textbook for the commercial first secondary class in Jordan. Unpublished Master These, Yarmouk University, Irbid, Jordan.

[14] Roe, D., Stoodt, R., Burns, C. (1978). Reading instruction in the secondary school, Revised edition. Chicago: Rand McNally College Publishing Co.

[15] Sengupta, S. (2002). Developing academic reading at tertiary level: A longitudinal study tracing conceptual change. The Reading Matrix, 2,(1), Retrieved December 29th, 2012 from Academic Search Premier EBSCO database (AN: 32548748). 
[16] Soars, J., \& Soars, L. (2006). New Headway Plus. Oxford: Oxford University Press.

[17] Williamson, G. L. (2008). A Text Readability Continuum for Postsecondary Readiness. Journal of Academics, 19 (4), $602-632$. Retrieved June 17th 2011 from Academic Search Premier EBSCO database (AN: EJ 822324).

Nasser M. Freahat is an assistant professor of English Language Curricula and Instruction. He is teaching English language courses for graduate and undergraduate courses in the English Language Department at Imam Mohammad Ibn Saud Islamic University-Riyadh, Saudi Arbia. His research interests include Language Acquisition, Teaching Reading Comprehension, and Discourse Analysis.

Oraib Hmoud Al-Faoury is an assistant professor of translation courses, TEFL and CALL in the English Language Department at Al-Imam Mohammad ibn Saud Islamic University $\backslash$ Riyadh. She has been teaching English at different colleges and universities for more than ten years. She has written and published research in creative short stories, giftedness, The Multiple Intelligence Theory, child rights and Whole Language Approach. 